\title{
Synthesis, Characterization and Photocatalytic Application of Halloysite-nanotube Supported Fe- Ni Nanostructure
}

\author{
Rahil S. Qureshi ${ }^{1}$, V. S. Ashtekar ${ }^{2}$, P. D. Jolhe ${ }^{3}$ \\ ${ }^{1,2}$ Sinhgad College of Engineering, Department of Chemical Engineering, Vadgaon, Pune -411041 \\ ${ }^{3}$ Sinhgad College of Engineering, Department of Biotechnology, Vadgaon, Pune -411041
}

\begin{abstract}
Fabricated halloysite and halloysite supported Fe-Ni (Fe-Ni@HNTs) nanostructure is successfully fabricated by immobilization of precursor metal over the surface of amino siliane modified HNTs. The as-sythesized HNTs supported metal nanostructures were characterized by X-ray diffraction (XRD), field emission scanning electron microscopy (FESEM) and energy dispersive X-ray spectrometry (EDX). Peaks patterns obtained from XRD confirm the formation immobilized HNTs and Fe-Ni@HNTs. 12 mol\% Fe-Ni@HNTs shows better photocatalytic oxidation of methylene blue (MB) than 6 mol\% Fe-Ni@HNTs under the influence of $U V$ irradiation. The effect of loading of catalyst had also been studied under this report.
\end{abstract}

Keywords: Halloysite, Photocatalytic, Methylene blue, Oxidation.

\section{Introduction}

In recent times, the preparation of enhanced and advance functional materials with improved properties and characteristics involve hybrid nano-compounds, which comprises nano-size inorganic and organic material derivatives, the important feature is controlling the growth of molecular structure at the atomic and macroscopic level dimensions, resulting a major effect in the performance [1-4]. All of the enhanced properties NCs can be can be prepared by inorganic solid such as, layered silica clay, hydroxylapatite, silicates, metal-oxides, and a variety of bio polymers, which includes polysaccharides, proteins, polypeptides, nucleic acid and much more [5-8] The synthetic method for the structural templating of the inorganic component normally by means of self assembly, preparation and surface modification of nano-scale inorganic materials [9-11]. They had a wide application in advanced catalysis, controlled drug preparation, advance oxidation processes, water purification, food processing, optics, mechanics, sensors and electronics [12-15].

The fabrication of novel material is now possible due to the development of halloysite based on organic-inorganic enhanced Nanocompounds, which will be used in applications as anti-corrosive agents, nanoreactors to host reactants for synthesis of nanomaterial. Halloysite nanotube (HNT) is a naturally occurred two-layered alumino-silicate clay $\left(\mathrm{Al}_{2} \mathrm{Si}_{2} \mathrm{O}_{5}(\mathrm{OH})_{4} \cdot n \mathrm{H}_{2} \mathrm{O}\right)$ having a hollow tubular shaped structure, which is formed of alumino-silicate minerals and consist of the constituent elements such as aluminium, silicon, and oxygen. The packing disorder and the nanotube curves are due to the adjacent alumina and silica layers with their certain amount of water of hydration and which roll up to form a several layers $[16,17]$. The hollow tube formation of aluminosilicate is impelled due to the mismatch in the periodicity between the tetrahedral $\mathrm{SiO}_{2}$ sheets and the adjacent octahedral $\mathrm{AlO}_{6}$ sheets, it also assist in determining the positive and negative surface charges of the HNTs $[18,19]$. Thus, they possess various varied surface chemistry that help to control the physico-chemical properties of these clay nanotubes through the organized chemistry of the constituent elements as well as their morphology. HNTs restrict their wides applications in different fields sometimes due to the hydrophilic surface. Hence organosilane had been used for the modification of the outer surfaces of the HNTs of these nanotubes which results in improved dispersive property of clay materials as well as improves the physical, mechanical, and chemical properties of the nanotubes.

The modification or functionalization of HNTs surfaces with these organosilanes provides the deposition of metal nanoparticles (NPs) all over the surface. where HNTs act as a solid inorganic support and organosilane is a linking molecule that link metal nanomaterial and HNTs and hence, leading to successful formation of HNTs/metal NCs. Due to the unique characteristics and properties of metallic nanoparticles had attracted a huge attention in research field in modern nanoscience technology and had a wide application of catalysis, electrical, electronics, photonics and information storage component [20-23]. Agglomeration had a great impact on their properties and activity which is highly affected and reduced once they start agglomerating. The mixture results in the formation of bulk like material. To avoid this problem of agglomeration and to posses well dispersed particles, Immobilization of these NPs on solid supports or deposit them directly over the supports are the way for preventing agglomeration [12, 24-28]. Halloysite nanoclay is available as abundant natural resource and hence is of low cost, therefore is a best alternate solid support for the deposition of metal NPs. The preliminary objectives of our present study are to synthesize HNTs/metal NCs, and studying its application in the photocatalytic degradation of dye. 


\section{International Journal of Science and Research (IJSR) \\ ISSN (Online): 2319-7064}

Index Copernicus Value (2015): 78.96 | Impact Factor (2015): 6.391

\section{Experimental}

\subsection{Functionalization of HNTs}

Preparation of functionalized HNTs was approached using the following experimental procedure. $40 \mathrm{~mL}$ of toluene and 4 gms of HNT's was charged in a $250 \mathrm{ml}$ three necke round bottom flask equipped with reflux condenser, thermowell for thermometer and stopper. The reaction mass in flask was heated using a heating mantle to achieve temperature of $60^{\circ} \mathrm{C}$. As $60^{\circ} \mathrm{C}$ is achieved $5 \mathrm{~mL}$ of (3aminopropyl triethoxy silane) is added to the reaction mass. The reaction mass is heated to gain reflux temp of 120 ${ }^{\circ} \mathrm{C}$, and reflux was carried out for next hrs. After $12 \mathrm{hrs}$, the reaction mass is cooled and then the material is centrifuged with simultaneous washing with toluene first and then with ethanol. The washed product is then dried at $80{ }^{\circ} \mathrm{C}$ for $5 \mathrm{hrs}$.

\subsection{Preparation of Fe-Ni@HNTs}

For the preparation Fe-Ni @ HNTs 9.95 gm FeSO $4.7 \mathrm{H}_{2} \mathrm{O}$ is added to $25 \mathrm{ml}$ of water in a beaker and agitated for 15 minutes at the agitation speed of $1200 \mathrm{rpm}$ using a magnetic stirrer. After that $1 \mathrm{gm}$ of functionalized halloysite is added to the solution then stirred continuously for $2 \mathrm{hr}$. $600 \mathrm{mg}$ of $\mathrm{NaBH}_{4}$ is added to the reaction mass and stirred for 30 minutes. 0.05 mole $\%$ and 0.125 mole $\%$ of $\mathrm{Ni}\left(\mathrm{NO}_{3}\right)_{2} \cdot 6 \mathrm{H}_{2} \mathrm{O}$ is added to the reaction mass and mixed for 30 minutes. The obtained product is then washed with distilled water and ethanol to wash off the reactant residue, centrifuged and dried at at $80{ }^{\circ} \mathrm{C}$ for $5 \mathrm{hrs}$. The obtained product is $\mathrm{Fe}$ $\mathrm{Ni} @ \mathrm{HNTs}$

\subsection{Photocatalytic experiments}

In all photocatalytic experiments, $100 \mathrm{ml}$ of dye solution and appropriate quantity Fe-Ni@HNTs of are taken in a beaker. The dye and catalyst suspension was agitated for 20 mins in dark chamber so that the adsorption equilibrium is reached. Then after 20 mins the UV radiation are illuminated on to the solution. At various time intervals $1 \mathrm{ml}$ from dye catalyst suspension is withdrawn and then is diluted to $10 \mathrm{ml}$ of solution by adding distilled water then centrifuge to separate suspended catalyst and its absorbance is measured. The absorbance is due to the colour of dye and it helps to calculate the concentration and degradation of dye.

\section{Results and Discussion}

\subsection{Photocatalyst characterization}

The XRD images shown in Fig. 1 give the XRD patterns of the modified HNTs and the prepared Fe-Ni@HNTs catalysts. For HNTs the peaks of diffraction is obtained at $27.5^{\circ}$, $38.6^{\circ}, 56.66^{\circ}$, and $64.06^{\circ}$ at $2 \theta$ corresponding to (111), (200), (220), and (311) that is allotted to hexagon structure of $\mathrm{Al}_{2} \mathrm{Si}_{2} \mathrm{O}_{5}(\mathrm{OH})_{4} \cdot n \mathrm{H} 2 \mathrm{O}$, the main skeleton of $\mathrm{Al}_{2} \mathrm{Si}_{2} \mathrm{O}_{5}(\mathrm{OH})_{4} \cdot n \mathrm{H} 2 \mathrm{O}$ is $\mathrm{Al}_{2} \mathrm{O}_{3}$ and $\mathrm{SiO}_{2}$. Where as in $5 \mathrm{~mol}$ $\% \mathrm{Fe}-\mathrm{Ni} @ \mathrm{HNTs}$ and $12 \mathrm{~mol} \% \mathrm{Fe}-\mathrm{Ni} @$ HNTs the diffraction peak is obtained at $26.9^{\circ}, 34.8^{\circ}, 46.76^{\circ}, 54.06^{\circ}$ and $27.2^{\circ}$, $39.6^{\circ}, 48.63^{\circ}, 58.06^{\circ}$ at $2 \theta$ corresponding to (111), (200),
(220), and (311) successful deposition of Fe-Ni over the surface of HNTs have been observed. It's also shows that several by products hav also been formed due may be due to the back reaction or the improper washing of the prepared catalyst. XRD patterns verify the F.C.C structure of the loaded Fe-Ni NPs.
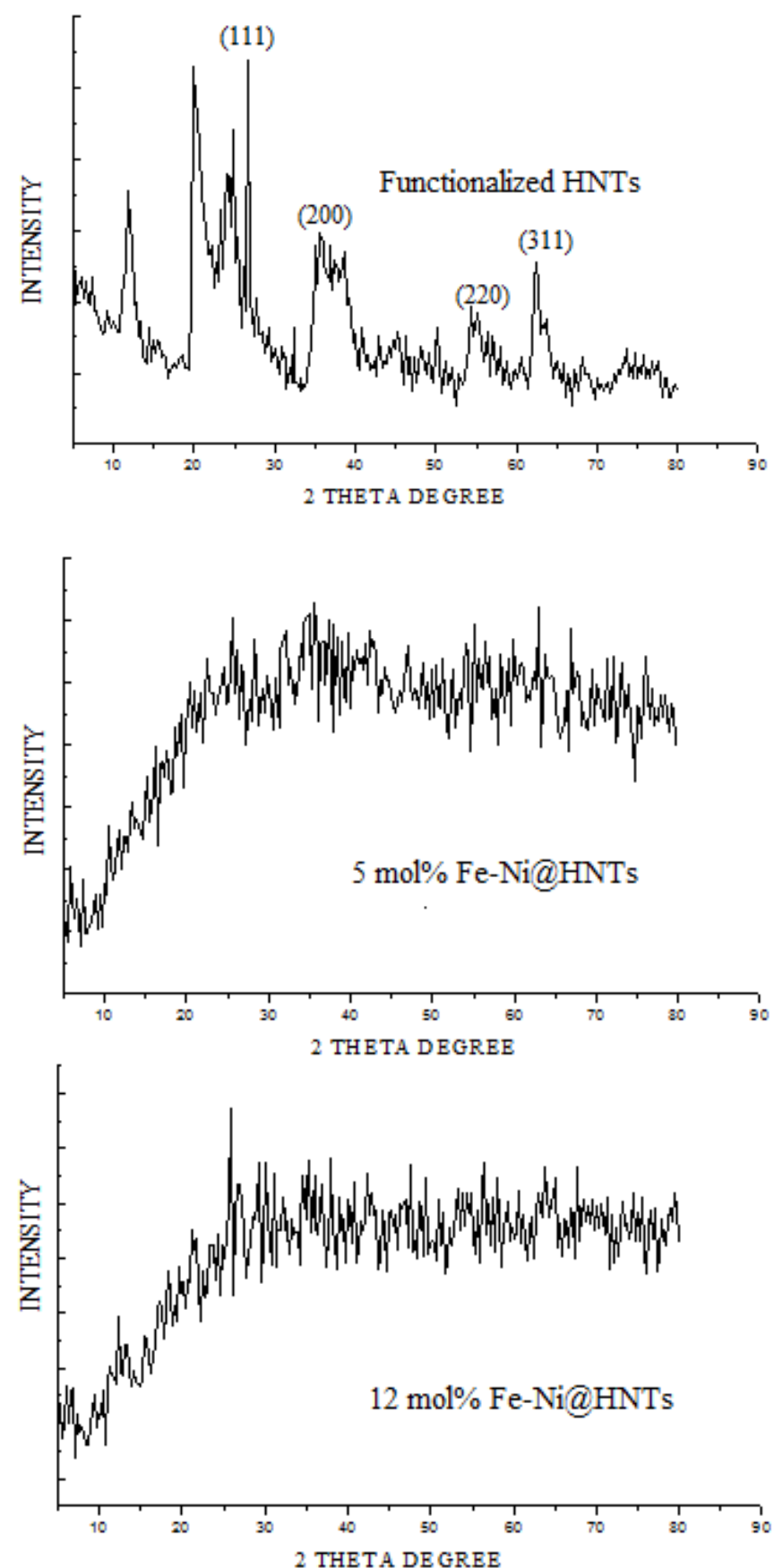

Figure 1: XRD patterns of functionalized HNTs and prepared 5 mol\% Fe-NI@HNTs and 12mole\% FeNi@HNTs.

Figure 2 and 3 shows the FE-SEM and EDX results of the prepared Fe-Ni@HNTs the morphologies and chemical composition of this prepared HNT/Fe-Ni. This shows that the $\mathrm{Fe}$ and $\mathrm{Ni}$ is completely im-mobilized and well deposited over the surface of HNTs having particle sizes $9.0 \pm 1.5$ for $\mathrm{Au}$ and $9.0 \pm 1.0$ for $\mathrm{Ag}$ NPs. Characterization by EDX analysis and the corresponding elemental mapping again reveals the formation of $\mathrm{HNTs} / \mathrm{Fe}-\mathrm{Ni} \mathrm{NCs}$.

\section{Volume 6 Issue 7, July 2017 www.ijsr.net}




\section{International Journal of Science and Research (IJSR) ISSN (Online): 2319-7064}

Index Copernicus Value (2015): 78.96 | Impact Factor (2015): 6.391

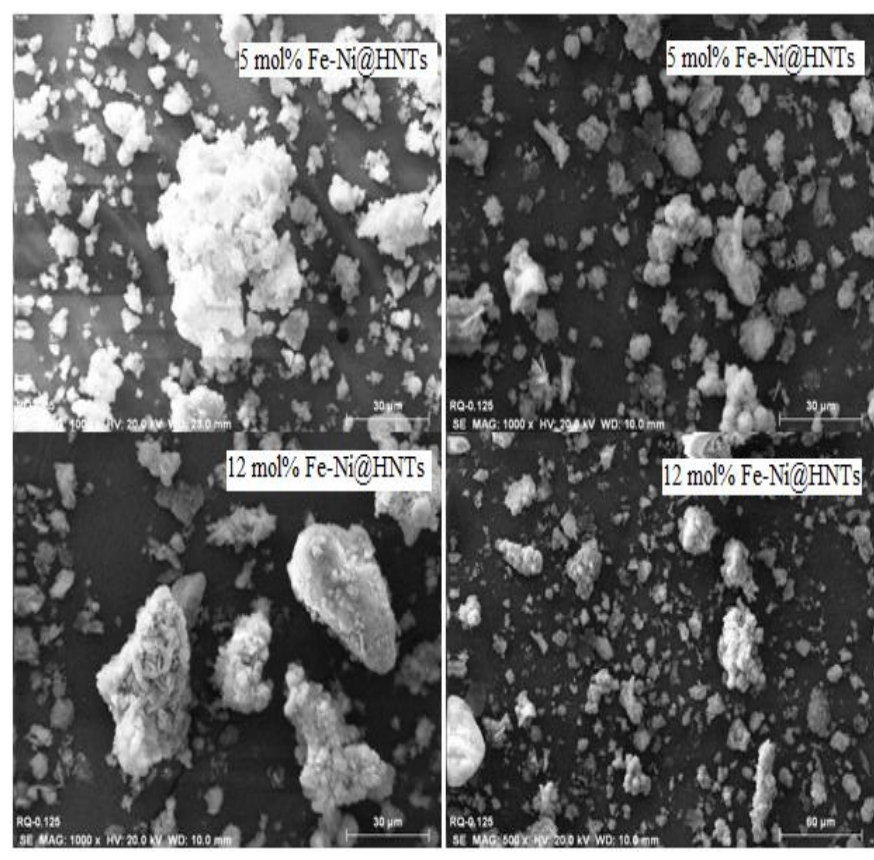

Figure 2: FE-SEM Images of $5 \mathrm{~mol} \%$ and $12 \mathrm{~mol} \% \mathrm{Fe}-$ Ni@HNTs at magnification of $30 \mu \mathrm{m}$ and $60 \mu \mathrm{m}$

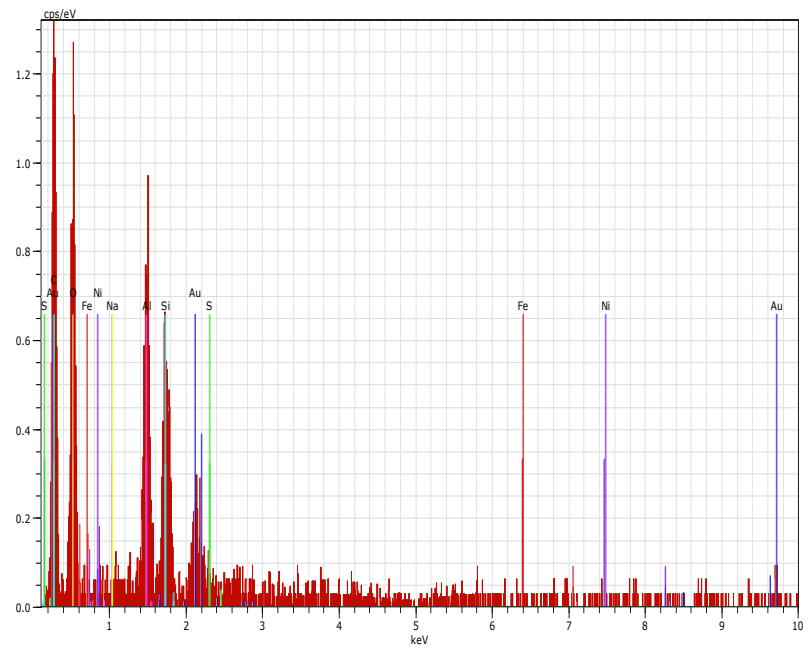

Figure 3: HNTs/Fe-Ni NCs and its EDX spectra, demonstrating the presence of $\mathrm{Fe}-\mathrm{Ni}$ in HNTs/Fe-Ni.

\subsection{Photocatalytic activity}

\subsubsection{Effect of Catalyst Loading}

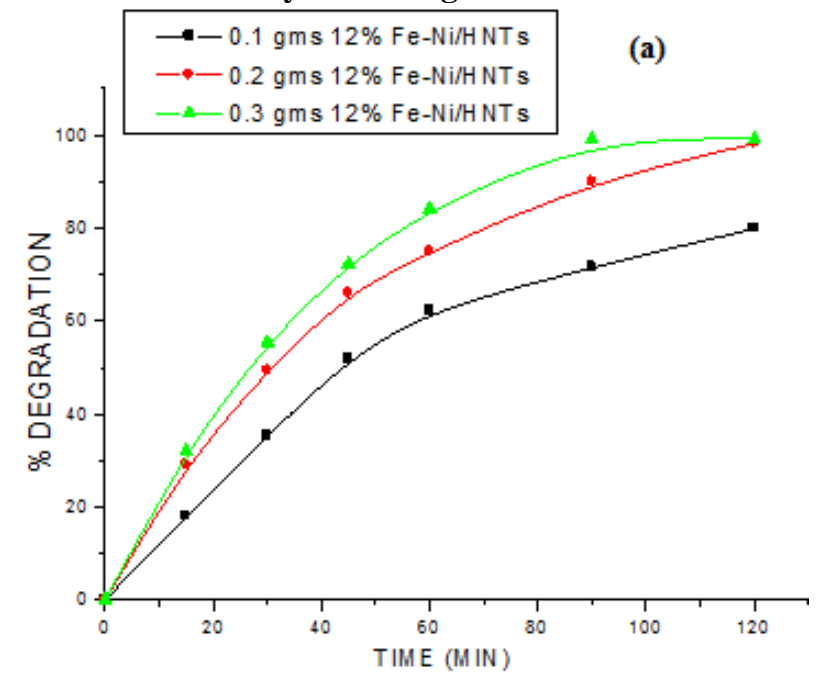

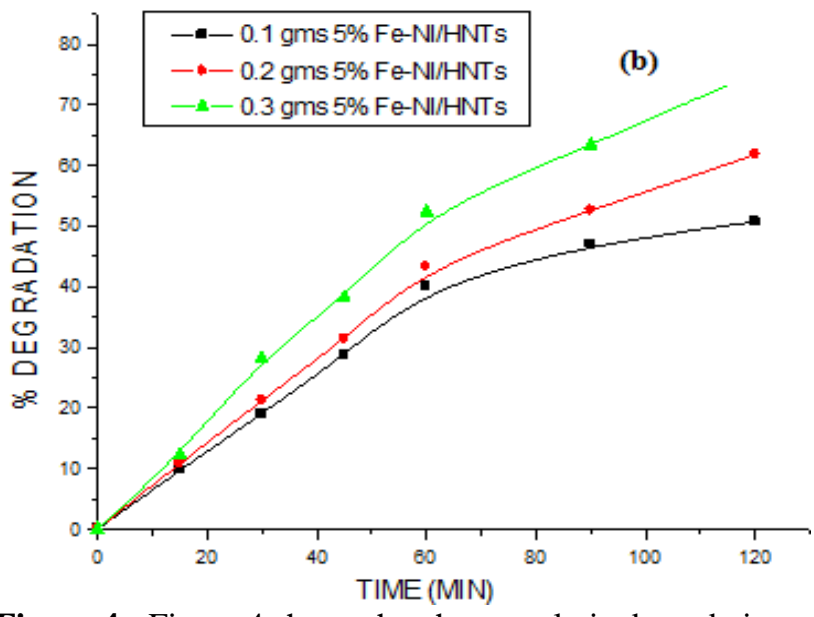

Figure 4: Figure 4 shows the photocatalytic degradation of [MB] by varying the amount of catalyst loading of catalyst (a) $5 \mathrm{~mol} \% \mathrm{Fe}-\mathrm{Ni} / \mathrm{HNTs}$ (b) $12 \mathrm{~mol} \% \mathrm{Fe}-\mathrm{Ni} / \mathrm{HNTs}$

The photocatalytic degradation of methylene blue is achieved by synthesized HNT/Fe-Ni. Fig 4 shows that the degradation of $\mathrm{MB}$ increases with increase in mole of $\mathrm{Ni}$ in the $\mathrm{Fe}$ $\mathrm{Ni@HNTs} \mathrm{dopant} \mathrm{with} \mathrm{respect} \mathrm{to} \mathrm{irradiation} \mathrm{time.} \mathrm{It} \mathrm{shows}$ that the MB degrades over the surface of Fe-Ni@HNTs. The photocatalytic degradation of $[\mathrm{MB}]$ is carried out for 120 minutes. Figure 4 relates the degradation of [MB] using various catalysts loading of $5 \mathrm{~mol} \% \mathrm{Fe}-\mathrm{Ni} @$ HNTs and 12 mol\% Fe-Ni@HNTs the maximum degradation occurs at loading of 0.3 gms of 0.3 gms 12 mol \% Fe-Ni@HNTs that is $(99 \%)$ followed by 0.2 gms of 12 mol \% Fe-Ni@HNTs that is $(98 \%)$.

\section{Conclusion}

In summary, modified HNTs and Fe-Ni@HNTs is successfully fabricated by immobilization of precursor metal over the surface of amino siliane modified HNTs and confirmed by XRD, FE-SEM, and EDX characterization technique. Prepared photocatalyst were applied for photocatalysis of methylene blue under UV radiations. Percent degradation 0.3 gms of 12 mol\% Fe-Ni@HNTs (99 $\%)$ is 3.6 times greater than 5 mol\% Fe-Ni@HNTs (75\%) may be due to the increase in concentration of $\mathrm{Fe}-\mathrm{Ni}$.

\section{References}

[1] C. Sanchez, B. Julián, P. Belleville and M. Popall, J. Mater.Chem., 2005, 15, 3559-3592.

[2] G. L. Drisko and C. Sanchez, Eur. J. Inorg. Chem., 2012, 5097-5105.

[3] Z. Ahmad and J. E. Mark, Mater. Sci. Eng., C, 1998, 6, 183-196.

[4] K. H. Wu, T. C. Chang, Y. T. Wang and Y. S. Chiu, J. Polym. Sci., Part A: Polym. Chem., 1999, 37, 22752284.

[5] B.K.G. Theng, Formation and Properties of Clay Polymer Complexes, Elsevier, New York, 1979.

[6] X. Ding and S. M. Henrichs, Mar. Chem., 2002, 77, 225-237.

[7] Y. Chen and J. O. Iroh, Chem. Mater., 1999, 11, 12181222 .

\section{Volume 6 Issue 7, July 2017 www.ijsr.net}


[8] C. C. Chang and W. C. Chen, Chem. Mater., 2002, 14, $4242-4248$.

[9] S. L. Burkett, S. D. Sims and S. Mann, Chem. Commun., 1996, 1367-1368.

[10] M. A. Ogawa, Chem. Commun., 1996, 1149-1150.

[11]D. G. Shchukin, G. B. Sukhorukov, R. R. Price and Y. M. Lvov, Small, 2005, 1, 510-513.

[12] S. Jana, S. Praharaj, S. Panigrahi, S. Basu, S. Pande, C.H. Chang and T. Pal, Org. Lett., 2007, 9, 2191-2193.

[13] A. F. Thunemann, D. Schutt, L. Kaufner, U. Pison and H. Mohwald, Langmuir, 2006, 22, 2351-2357.

[14] S. J. Tans, A. R. M. Verschueren and C. Dekker, Nature, 1998, 393, 49-52.

[15] S. Lelu, C. Novat, A. Guyot and E. Bourgeat-Lami, Polym. Int., 2003, 52, 542-547.

[16]E. Joussein, S. Pitit, J. Churchman, B. Theng, D. Righi and B. Delvaux, Clay Miner., 2005, 40, 383-426.

[17] Y. M. Lvov, D. G. Shchukin, H. Möhwald and R. R. Price, ACS Nano, 2008, 2, 814-820.

[18] E. Abdullayev, A. Joshi, W. Wei, Y. Zhao and Y. Lvov, ACS Nano, 2012, 6, 7216-7226.

[19] G. Cavallaro, G. Lazzara and S. Milioto, J. Phys. Chem. C, 2012, 116, 21932-21938.

[20]D. B. Ingram, P. Christopher, J. L. Bauer and S. Linic, ACS Catal., 2011, 1, 1441-1447.

[21] J. S. Lee, P. A. Ulmann, M. S. Han and C. A. Mirkin, Nano Lett., 2008, 8, 529-533.

[22]L. R. Hirsch, R. J. Stafford, J. A. Bankson, S. R. Sershen, B. Rivera, R. E. Price, J. D. Hazle, N. J. Halas and J. L. West, Proc. Natl. Acad. Sci. U. S. A., 2003, 100, 13549-13554.

[23] C. J. Murphy, A. M. Gole, S. E. Hunyadi and C. J. Orendorff, Inorg. Chem., 2006, 45, 7544-7554.

[24] J. Dai and M. L. Bruening, Nano Lett., 2002, 2, 497501.

[25] S. Ivanova, V. Pitchon, Y. Zimmermann and C. Petit, Appl. Catal., A, 2006, 298, 57-64.

[26] S. Jana and S. Das, RSC Adv., 2014, 4, 34435-34442.

[27] K. Esumi, R. Isono and T. Yoshimura, Langmuir, 2004, 20, 237-243.

[28] J. C. Garcia-Martinez, R. Lezutekong and R. M. Crooks, J. Am. Chem. Soc., 2005, 127, 5097-5103.

[29] M. Haruta, S. Tsubota, T. Kobayashi, H. Kageyama, M. J. Genet and B. Delmon, J. Catal., 1993, 144, 175-192. 